
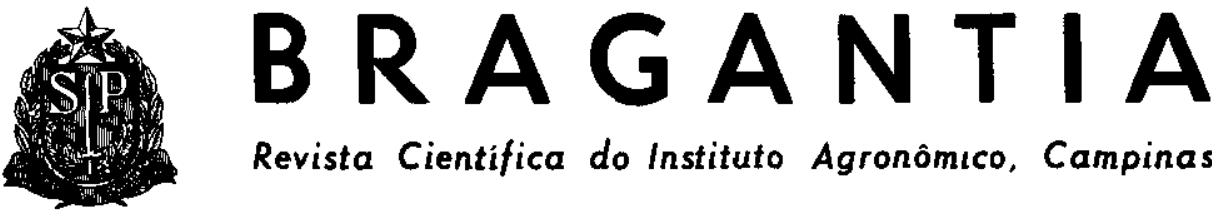

Revista Cientifica do Instituto Agronômıco, Campinas

\title{
OCORRENCIA DE LARVAS DE DIABROTICA SPECIOSA (GERMAR, 1824) DANIFICANDO VAGENS E SISTEMA RADICULAR DE AMENDOINZEIRO ( ${ }^{1}$ )
}

Andre Luiz Louranção (2), CarLos Jorge Rossettro, Seção de Entomologia Fitotécnica, Instituto Agronômico, Dalmo Henrique de Campos Lasca, Grupo de Oleaginosas, Vhra Lúcu PaluA, Casa da Agricultura de Urânia, e GeYsa JoseFINA Palla, Delegacia Agricola de Jales, Coordenadoria de Assistência Téenica Integral.

A vaquinha, Diabrotica speciosa (Germar, 1824) (Coleoptera: Chrysomelidae) é um coleóptero que ocorre em diversos Estados brasileiros (8), sendo bastante comum em São Paulo, onde, através de levantamentos de insetos realizados com armadilhas luminosas, apresentou-se com maior freqüêhcia nos meses mais quentes do ano $(2,4,9)$.

Os adultos de $D$. speciosa se alimentam das folhas de grande número de espécies vegetais (8); as larvas, que são subterrâneas, desenvolvem-se às expensas de raízes. Os adultos danificam folhas de feijoeiro, soja, bananeira, batatinha, cucurbitáceas, tomateiro $(5,6)$, lentilha, fava, ervilha, girassol, berinjela, pimentão (5), fumo e hortaliças (6). As larvas podem perfurar tubérculos de batatinha $(5,6)$, provocando 0 aparecimento de pequenas pontuações necróticas que depreciam comercialmente o produto. AMANTE \& FIGUEIREDO JR. (1) assinalaram a ocorrência de larvas deste crisomelídeo danificando o sistema radicular de feijoeiro (Phaseolus vulgaris L.). Segundo esses autores, os sintomas do ataque se verificavam em reboleiras, sendo que as plantas atacadas amareleciam $e$ as folhas secavam progressivamente. SICHMANN (7), sem mencionar a espécie, relatou que larvas de Diabrotica podem eventualmente atacar o amendoinzeiro sem, contudo, causar danos de vulto.

(1) Recebida para publicação a 17 de funho de 1982.

(?) Com bolsa de suplementaçăo do CNPq. 
Vol. 41, Nota n. ${ }^{\circ} 10$

No cultivo da seca de 1982 , plantio de fevereiro, no município de Urânia (SP) ocorreu forte infestação de larvas de $D$. spepeciosa em 4,5 alqueires de amendoim, danificando o sistema radicular e as vagens das plantas. A área cultivada com irrigação foi tratada com carbofuran no plantio e o cultivar utilizado foi 0 Tatu. As raízes, as radículas e a parte subterrânea dos ginóforos apresentavam pronunciadas lesões decorrentes da alimentação das larvas e, não raro, estavam totalmente cortadas. As vagens mostravam orifícios por onde as larvas penetravam para se alimentar nos grãos. O ataque ocorreu antes da fase de maturação dos grãos que, quando atacados, se tornavam totalmente deformados e sem valor comercial. Em funçăo da alta infestação verificada através de inspeções nessa lavoura, foi considerada antieconômica a colheita da área cultivada.

E conhecida na literatura brasileira a ocorrência de adultos de $D$. speciosa alimentando-se em folhas de amendoinzeiro $(3,8)$; também existe a citação de que Diabrotica pode ocasionalmente atacar o sistema radicular desta planta sem causar-lhe grandes danos (7). Não é, todavia, do conhecimento dos autores o relato prévio de um surto de larvas de D. speciosa danificando raízes e vagens desta oleaginosa e causando grandes prejuízos à cultura.

\section{OCCURRENCE OF LARVAE OF DIABROTICA SPECIOSA (GERMAR, 1824) DAMAGING PODS AND ROOTS OF PEANUT (ARACHIS HXPOGAEA L.)}

\section{SUMMARY}

In April 1982, at Urânia, State of Säo Paulo, Brazil, a high infestation of larvae of Diabrotica speciosa (Germar, 1824) (Coleoptera: Chrysomelidae) damaging roots, gynophores and pods of an irrigated peanut crop was observed. The roots, radicles and gynophores showed lesions due to the attack of the larvae; sometimes these plant parts were completely destroyed. The pods presented holes through which the larvae penetrated in order to eat the seeds. Because of the high infestation and the heavy damage the harvest of the crop was considered not economical.

\section{REFERENCIAS BIBLIOGRAFTCAS}

1. AMANTE, E. \& FIGUEIREDO JR., E. Nota prévia sobre a ocorrencia da larva da Diabrotica speciosa Germar, 1824 (Coleoptera. Galerucidae), em raízes de feijấ (Phaseolus vulgaris). In: SINEPOSIO BRASIIEIRO DE FEIJAO, 1., Campinas, 1971. Resumos. p.37-38.

2. BUSOLI, A. C. Levantamento, constäncia e flutuação populacional de alguns insetos coletados com armadilhas luminosas em Jaboticabal, SP. Piracicaba, Escola Superior de Agricultura "Luiz de Queiroz", 1979. 100f. (Dissertaçăo de Mestrado)

3. CASTRO, P. R. C.; PITELLI, R. A.; PASSILONGO, R. L. Varlaçōes na ocorrência de algumas pragas do amendoinzeiro relacionadas com o desenvolvimento da cultura. Anais da Sociedade Entomológica do Brasil, Itabuna, 1(1):5-16, 1972. 
4. CIVIDANES, P. J.; SILVEIRA NETO, S.; BOTELHO, P. S. M. Flutuação populacional de Chrysomelidae coletados com armadilhas luminosas em regiōes canavieiras de Sảo Paulo. O Solo, Piracicaba, 72(1):45-51, 1980.

5. Gallo, D.; NaKaNo, O.; SILVEIRA NETO, S.; CARVALHO, R. P. L.; Batista, G. C. de; BERTI FILHO, E.; PARRA, J. R. P.; ZUCCHI, R. A.; ALVES, S. B. Manual de entomologia agricola. Săo Paulo, Ceres, 1978. 531p.

6. MARICONI, F. A. M. Inseticidas e seu emprego no combate às pragas. São Paulo. Nobel, 1976. 466p. t.2.

7. SICHMANN, W. Amendoim protegido dá mais lucro. FIR Revista Brasileira de Fertilizantes, Inseticidas e Rações, Sāo Paulo, 10(1):60-100, 1967.

8. Silva, A. G. d'A. e; GonÇAlves, C. R.; Galvão, D. M.; GONÇAlves, A. J. L.; GOMES, J.; SILVA, M. do N.; SIMONI, L. de. Quarto catálogo dos insetos que vivem nas plantas do Brasil, seus parasitos e predadores. Rio de Janeiro, Ministério da Agricultura, 1968. 622p. pt. 2, t.1.

9. SILVEIRA NETO, S. Levantamento de insetos e flutuação da populaçāo de pragas da ordem Lepidoptera, com o uso de armadilhas luminosas, em diversas regiōes do Estado de São Paulo. Piracicaba, Escola Superior de Agricultura "Luiz de Queiroz", 1972. 183f. (Tese de Livre-Docência) 